\title{
A Survey on Methods for Broadband Internet Access on Trains
}

\author{
Daniel T. Fokum, Student Member, IEEE and Victor S. Frost, Fellow, IEEE
}

\begin{abstract}
We present a survey of approaches for providing broadband Internet access to trains. We examine some of the barriers that hinder the use of broadband Internet on trains and then discuss some of the opportunities for broadband deployment to trains. This survey considers some of the basic concepts for providing broadband Internet access and then reviews associated network architectures. The review of network architectures shows that we can subdivide networks for providing broadband Internet access to trains into the train-based network, the access network-for connecting the train to the service provider(s) - and the aggregation network-for collecting user packets generated in the access network for transmission to the Internet. Furthermore, our review shows that the current trend is to provide Internet access to passengers on trains using IEEE 802.11; however, a clear method for connecting trains to the global Internet has yet to emerge. A summary of implementation efforts in Europe and North America serves to highlight some of the schemes that have been used thus far to connect trains to the Internet. We conclude by discussing some of the models developed, from a technical perspective, for testing the viability of deploying Internet access to trains.
\end{abstract}

Index Terms-Broadband Internet, Trains, FAMOUS, Architecture

\section{INTRODUCTION}

W ITH the explosion in growth of the Internet in the last 20 years, people have a much higher expectation of being able to get on the Internet independent of location. Until recently, trains and airplanes have been two locations where passengers have not necessarily been able to achieve high-speed Internet connections. In the particular case of trains, providing Internet access to passengers on board trains makes good business sense: Internet access for passengers can provide a revenue stream for the train company while attracting more travelers. For example, a 2004 study in the United Kingdom found that $72 \%$ of business travelers were more likely to use trains than cars or airplanes if $\mathrm{Wi}-\mathrm{Fi}$ access was available on trains. This study also found that $78 \%$ of these business travelers would use Wi-Fi access if it was made available on trains [1]. In the case of freight trains, Internet access can allow for real-time or near-real-time tracking of freight-related events on board the train, potentially resulting in a decrease in insurance charges to the freight carrier. In addition to these benefits, broadband Internet access

Manuscript received August 29, 2008; revised March 7, 2009; revised July 10, 2009; accepted July 28, 2009. This work was supported in part by Oak Ridge National Laboratory (ORNL) — Award Number 4000043403. This material is also partially based upon work supported while V.S. Frost was serving at the National Science Foundation.

D.T. Fokum and V.S. Frost are with the Information and Telecommunication Technology Center, The University of Kansas, Lawrence, KS, 66045 USA; (e-mail: fokumdt@ittc.ku.edu; frost@ittc.ku.edu)

Digital Object Identifier 10.1109/SURV.2010.020510.xxxxx on trains can also enhance the safety of the train by allowing an operations center to monitor, in real-time, train-related data, as in [2].

Internet access on board trains is already available today in parts of Europe. For example, beginning in July 2004, a British train operator, GNER, ${ }^{1}$ began offering Internet access on some of its trains [3]. In 2005 another British company, Nomad Digital, claimed to have addressed the problem of providing high-speed Internet access to passengers on Southern Trains' London to Brighton route using WiMax [4]. In what follows, we provide an overview of communications on board trains, beginning with some of the earliest papers discussing broadband Internet access for users on the move.

The main contribution of this paper is to provide a survey of research and implementations that aim to make Internet access available on trains. The conditions of a rail environment that make communications from trains difficult are highlighted. For reasons that shall become apparent later, we make distinctions between work done in Japan, Europe, and North America, due to the different characteristics of rail transportation in those locations. The rest of this paper is laid out as follows: Section II lists the issues hindering high-speed communications from trains. Section III introduces a reference architecture for Internet access on trains, and also provides some context on handoff and addressing issues related to trains. Section IV provides discussion on initial concepts that have guided the deployment of broadband Internet access to trains. In Section $\mathrm{V}$ we provide a taxonomy of technologies used to connect trains to the Internet. Section VI discusses results from testbeds that have examined how to deploy broadband Internet to trains. In Section VII we present the efforts made, or those efforts underway, to carry out high-speed communications from trains. Section VII is further subdivided into examining implementation efforts underway in Europe and North America. Section VIII presents business models developed to determine the viability of providing broadband Internet access on trains. In Section IX we provide a summary of the lessons learned from deploying broadband Internet to trains. Finally, in Section $\mathrm{X}$ we provide concluding remarks.

\section{DifFICULTIES AND OPPORTUNITIES}

\section{A. Difficulties}

Communications on board trains are complicated by several factors. Lannoo et al. [5] state that railcars have Faraday cagelike characteristics which can lead to high penetration losses

${ }^{1}$ GNER subsequently lost its license to operate the East Coast Mainline, where the Wi-Fi-enabled trains were deployed. National Express replaced GNER on the East Coast Mainline, and they offer free wireless (Wi-Fi) Internet access on all trains on the East Coast line. 
TABLE I

ABBREVIATIONS

\begin{tabular}{|l|l|}
\hline Term & Definition \\
\hline ADSL & Asymmetric Digital Subscriber Line \\
\hline AGW & Access Gateway \\
\hline BS & Base station \\
\hline CL-IP & Convergence Layer IP \\
\hline CL-MAC & Convergence Layer MAC \\
\hline DVB-RCS & Digital Video Broadcasting-Return Channel via Satellite \\
\hline DVB-S & Digital Video Broadcasting-Satellite \\
\hline DVB-S2 & Digital Video Broadcasting-Satellite-Second Generation \\
\hline FLASH-OFDM & Fast Low-latency Access with Seamless Handoff-Orthogonal Frequency Division Multiplexing \\
\hline GPRS & General Packet Radio Service \\
\hline GVC & Ground-to-vehicle communications \\
\hline HSDPA & High-Speed Downlink Packet Access \\
\hline LCX & Leaky Coaxial cable \\
\hline MAR & Mobile Access Router \\
\hline MIMO & Multiple Input-Multiple Output \\
\hline MMP-SCTP & Mobile Multi-Path Stream Control Transport Protocol \\
\hline OVC & On board vehicle communications \\
\hline PDF & Policy Decision Function \\
\hline QoS & Quality of Service \\
\hline RAU & Remote Antenna Units \\
\hline SCTP & Stream Control Transfer Protocol \\
\hline SGW & Service Gateway \\
\hline SWiFT & Seamless Wireless Internet for Fast Trains \\
\hline TAT & Train Access Terminal \\
\hline TMS & Train Management System \\
\hline UMTS & Universal Mobile Telecommunications System \\
\hline UMTS-FDD & Universal Mobile Telecommunications System - Frequency Division Duplex \\
\hline VLAN & Virtual Local Area Network \\
\hline WiMax & Worldwide Interoperability for Microwave Access \\
\hline WLAN & Wireless local area network \\
\hline
\end{tabular}

for signals. Beeby [6] adds that other complicating factors include:

- A "high vibration environment" that may require mechanical isolation of communication devices.

- A "thermally challenging" environment, since heat may be a significant issue in certain parts of the train.

- A harsh electrical environment due to:

- The proximity of high voltages, as in electrical trains.

- High magnetic fields, as in magnetic levitation (Maglev) trains.

- Trains are not designed to provide a "clean" electrical supply for computers.

- The need to have equipment with minimal maintenance schedules - this may result in equipment with near military-grade specifications.

- The presence of trackside features, such as railway signaling equipment.

Some other factors hindering communications on trains include:

- Railway companies constantly add or remove rail cars from trains. As a result, it is necessary for the communications network to discover these changes automatically [7].

- Poor coupler contacts on rail vehicles, which may introduce communications failures [7].

- Tunnels may limit visibility to wireless communication infrastructure.
- Frequent handoffs ${ }^{2}$ in the cellular network. These handoffs can result in packet loss and packet reordering [8].

- The train's mobility complicates the provision of quality of service to different traffic flows [9].

In spite of these difficulties, there are several opportunities to provide Internet access on trains using a variety of technologies, including Wi-Fi, WiMax, satellite technologies, and radio-over-fiber. In Section II-B we discuss some of these opportunities.

\section{B. Opportunities}

The growth in wireless communication technologies over the last two decades opens up several opportunities for supporting communication on board trains. For example, customers in a stationary train can have Internet access through the existing cellular infrastructure without many modifications, except for an antenna on the outside of the train. Issues arise only when the train begins to move, particularly at high speeds, and requires several handoffs in a short period of time. Beeby [10] argues that communications capabilities on mobile terminals is constantly improving, with some phones now having multiband and Wi-Fi capabilities. Currently it is standard to have Wi-Fi integrated on laptops, and eventually WiMax might also be commonly available. These factors, especially the latter, have the potential to drive Internet usage higher, particularly because as connectivity becomes more

\footnotetext{
${ }^{2}$ To see why this might be a problem, consider a train travelling at $30 \mathrm{~m} / \mathrm{s}$ $(108 \mathrm{~km} / \mathrm{h})$ through an environment with cell sizes on the order of $3 \mathrm{~km}$. Then we would have handoffs every $100 \mathrm{~s}$.
} 
prevalent, usage increases [10]. Beeby [10] goes on to argue that there are significant opportunities available for Internet access on trains if access to the technology can be made: simple, ubiquitous (as in not requiring any special software or terminal), and useable (that is, acceptable throughput and delay with few service interruptions). In this respect, Fourth Generation $(4 \mathrm{G})$ communications technologies, such as WiMax, IEEE 802.16m [11], or LTE [12] may be good solutions for offering Internet access on trains. It has been reported that WiMax is being used in the UK to provide Internet access for Southern Trains [4], [13]-[15]. We expect further growth in broadband Internet access availability on trains as more train operators are convinced of the business viability of negotiating for wireless coverage along their tracks using WiMax or some other $4 \mathrm{G}$ technology.

Another application for broadband communication on trains is railway signaling. Aguado et al. [16] note that standardsbased communications systems such as IEEE 802.16 [17] and IEEE 802.20 (Mobile Broadband Wireless Access) [18] can be used for railway signaling instead of the cable-based systems currently in use.

\section{REFERENCE ARCHITECTURE}

In this section we present a reference architecture to guide our discussion of broadband Internet access on trains. We also provide some context on handoff and addressing issues that are common to all Internet deployments on trains.

Fig. 1 shows a logical architecture for the computer networks aboard the trains used to provide Internet access to passengers. This architecture, which incorporates aspects of the train communication management platform from [19], uses gateways in each train car to build a train-level network. Broadband Internet access on the train is provided through the Train Access Terminal (TAT). This terminal, which can support one or many technology types, connects to the access network using an antenna mounted on the outside of one train car. The incoming signal from the train access terminal is then fed to gateways and wireless access points in all the rail cars in the train. Within each rail car IEEE 802.11 [20] is commonly proposed to provide connectivity to passengers; however, passengers may also connect to a wired network in the railcar, if one is available. The benefits of using such an architecture include the following:

- The cellular network system is not put under strain attempting to make handoffs for many fast moving users simultaneously [21]. Furthermore, emerging Internet Engineering Task Force (IETF) protocols for network mobility [22] can be deployed to manage TAT handoffs.

- The train access terminal can combine different access technologies. The TAT can also implement some "intelligence" to select the best means of communication between the train and the access network, as in [21].

Fig. 2 shows a train connected to the Internet using the reference architecture presented in this paper. This architecture for Internet access on trains is layered and consists of the access network, aggregation network, and the service providers' networks. The access network (shown here as composed of base stations) is close to the train tracks, and it provides the last hop communications for the train access terminal. The aggregation network lies between the access network and the service providers' networks, and it forwards data from the access network to the global Internet. The access gateway in the architecture combines the data from a group of users into a tunnel and forwards that data to the service gateway. The service gateway serves as an interface between the aggregation network and service providers' networks. Van Quickenborne et al. [23] argue that aggregated tunnels per train are suitable for this architecture since they are more manageable and efficient than a per user connection scheme. From the reference architecture diagram, we can also see that there are different technology options, including satellite technologies, for the access and aggregation networks. This observation is in agreement with Conti [14], who states that currently there is general agreement on how to provide Internet access to passengers aboard trains. A disagreement arises on the best method to connect moving trains to the Internet backbone, i.e., how to connect the antenna on the train access terminal to the access network. However, the widespread deployment of $4 \mathrm{G}$ technologies may lead to some consensus on the best way to do this.

It should be noted that Fig. 2 combines features of several proposed architectures, including the FAMOUS architecture [8] that we will see later in this paper. Some other features of this architecture include:

- The access network is a wireless network with base stations along the train tracks. The access network can use either GPRS [13] and [14], HSDPA [24], WiMax [4], [13]-[15], Wi-Fi [25], FLASH-OFDM [26], satellite links [14], IEEE 802.20 [27], or radio-over-fiber [5].

- The aggregation network can use the following technologies for forwarding data: IEEE 802.11 [28], Ethernet [8], ADSL [14], or optical fiber [15].

- Virtual Local Area Networks (VLANs) are preferred in Ethernet-based aggregation networks to carry aggregated traffic flows from the access gateway to the service gateway [8].

- Satellite links ${ }^{3}$ can be used to provide Internet access to trains; however, they do not fit this architecture neatly, since the satellite ground station cannot be easily classified as either a service gateway or an access gateway. Consequently, the satellite links in Fig. 2 are shown straddling the different networks.

- The train access terminal may support different access technologies. Rodriguez et al. [29] implement a prototype terminal that combines several wireless access technologies to create a mobile hotspot. Experimental results show that such a device provides much better network throughput than if a single access technology was used.

\section{A. Other Architectures}

Kanafani et al. [30] propose an architecture for Internet access on trains that is based on open standard radio tech-

\footnotetext{
${ }^{3}$ Lannoo et al. [5] state that satellite communications are not ideal for highspeed access to trains since satellite links have limited bandwidth and long round trip times $(\mathrm{RTT})$.
} 




Fig. 1. Architecture for Internet Connectivity between Rail Cars

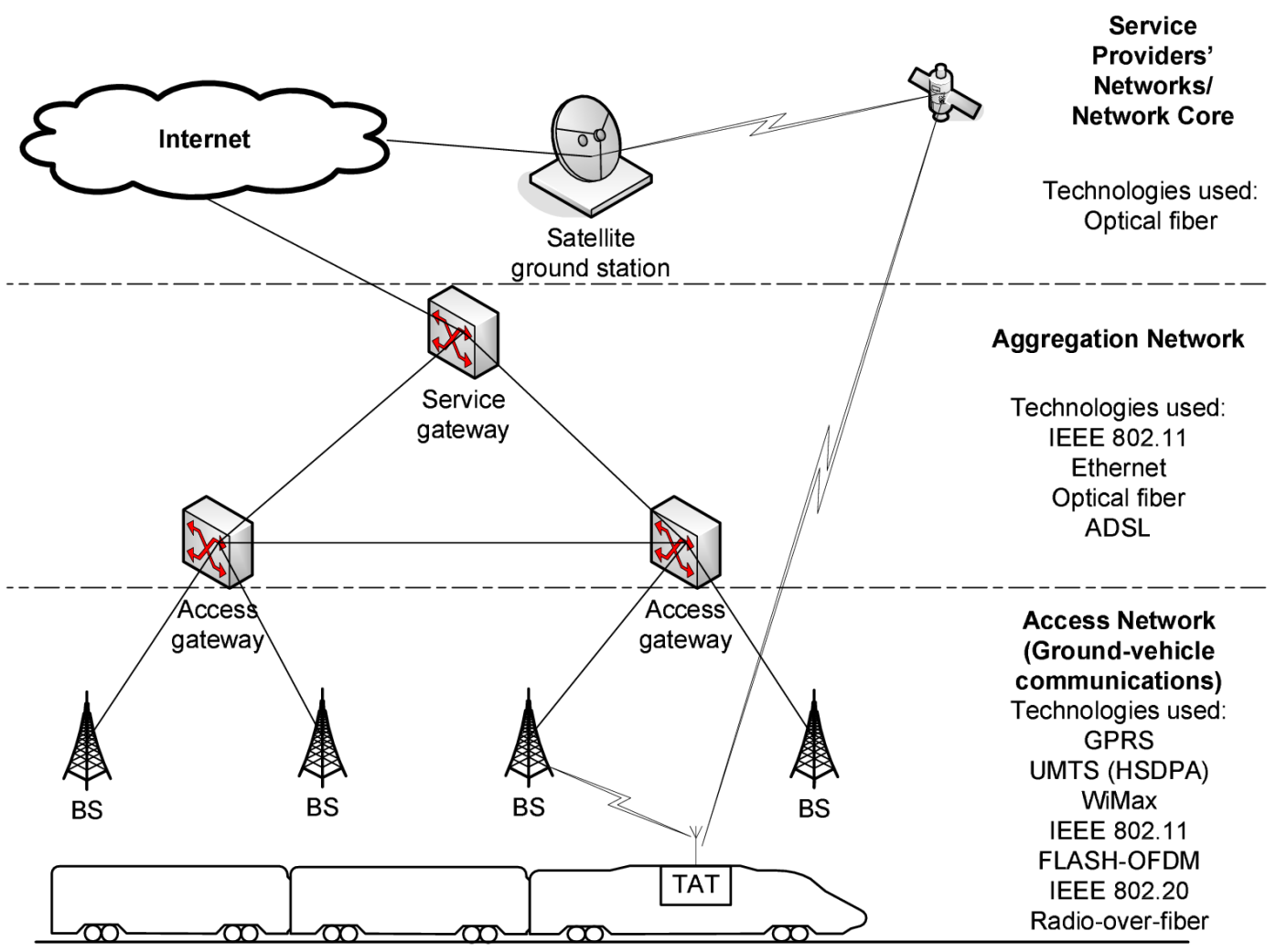

Fig. 2. Reference Architecture for Internet Access on Trains

nologies, such as IEEE 802.11 and IEEE 802.16, Mobile IP [31], in-train network components, train to backhaul architecture components, a trackside communication system, a homeland security surveillance system, and command and control centers. In addition, the architecture proposed in [30] has a subsystem that handles handoffs as the train moves from the coverage area of one trackside unit to the next. The train to backhaul component in [30] is analogous to the train access terminal in Fig. 1. The trackside communication system is the access network, while the in-train network is the same as the network shown in Fig. 1.

Riihimaki et al. [32] introduce an architecture that divides train communications into backhaul connections, Ground-tovehicle communications (GVC) and on board vehicle communications (OVC). The GVC is analogous to the access network in the reference architecture in Fig. 2, while the OVC network consists of customer devices as well as other networking devices, such as a train server, placed in the train. The OVC network is similar to the train-based network shown in Fig. 1. On board each train the OVC and GVC are connected through 
a connection manager $(\mathrm{CM})$, which is analogous to the train access terminal in Fig. 1 [32].

\section{B. Handoff Issues}

In 2003 it was observed that popular Internet applications may not be available at high speeds due to lack of bandwidth, poor quality of service, and frequent handoffs [33]. These problems could be partially addressed by: increasing network bandwidth using smart antenna systems and MIMO technologies, as well as improved handoff protocols that prevent connection loss when moving from one base station to another. Van Leeuwen et al. [33] state that the technologies discussed above are not sufficient to support broadband communications at high speeds; new modulation schemes and context-aware applications are also needed to achieve high data rates in fast moving vehicles.

1) Train Access Terminal Handoffs: De Greve et al. [8] stated in 2005 that high link speeds for end users could only be achieved in cellular networks by reducing the cell size to efficiently reuse spectrum. However, small cells also mean more handoffs between cells. Furthermore, Mobile IP is not a good protocol for delivering high link speeds to fast moving users since Mobile IP does not work well with frequent handoffs due to handoff latency, handoff packet loss, and control message load. As a result, [8] stated that higher link speeds could be offered to fast moving users on a train by using small cells operating in the millimeter wave band. In addition, these authors suggest using radio-over-fiber with moveable cells to reduce handoff times, an idea that is an extension of Gavrilovich's moving base stations model [34]. We will revisit this concept in Section V-A.

In 2007 Pareit et al. [21] assumed that several different access technologies need to be combined to provide broadband Internet access on trains. As a result, they tackle the issue of handoffs as the train moves from the coverage area of one access technology to another. To prevent the access network from having to make several simultaneous handoffs, it is proposed that train passengers connect to the Internet via on board Wi-Fi access points that are connected to the local train network. The architecture proposed in [21] places a Policy Decision Function (PDF) on the train access terminal, between the train's network and the outside world. The PDF decides which interface should be used to provide the connection between the train and the access network. This decision is based on link quality, train location and speed, and possibly cost or load balancing. Mobility Management modules are the other key part of the architecture. They reside partly on the train and partly on the Central Management System. These modules take input from the PDF to make handoffs as smooth as possible.

Pareit et al. [21] evaluate the feasibility of using either Mobile IP or MMP-SCTP (Mobile Multi-Path Stream Control Transport Protocol) [35] for a mobility management handoff protocol. Mobile IP allows nodes to change their point of attachment to the Internet without changing their IP address [21], while Stream Control Transport Protocol (SCTP) is a reliable transport protocol that resides above an unreliable connectionless packet service [21]. SCTP allows for the detection and retransmission of packets that might be lost during a handoff. In addition, SCTP endpoints allow for multihoming. In [21] it is shown that MMP-SCTP displays better performance than Mobile IP after a slow start for TCP performance without a handoff. Pareit et al. emulate the case where a train passenger gets Internet access using a satellite link and an HSDPA [36] link. Reference [21] shows that for a satellite link, Mobile IP exhibits better performance than MMP-SCTP (also after the slow start). When there is a handoff between satellite and HSDPA, ${ }^{4}$ we see that Mobile IP does not require any retransmissions, and all packets arrive in order. Very similar results were obtained when the same test was performed using MMP-SCTP [21]. Pareit et al. [21] conclude by noting that MMP-SCTP and Mobile IP are able to handle predicted handoffs seamlessly. In spite of its overhead, MMP-SCTP can be a better choice for a mobility management protocol since it does automatic retransmissions.

2) Passenger Handoffs: In 2005 Jooris et al. [37] studied seamless handoff, roaming, Quality of Service (QoS), and connections between heterogeneous wireless networks, such as the on board network and the trackside network. On each train the Mobile Access Router (MAR) - which is analogous to the train access terminal (TAT) in Fig. 1-will have one interface for each type of technology, and it will constantly choose the best link from the train to the outside world. Aboard a train, handoffs can occur when a mobile device is either unplugged from the train's wired network or when a mobile user moves from one Wi-Fi hotspot on the train to another. In each case the user's session must be protected. Jooris et al. [37] propose carrying out this protection by creating a convergence layer that hides the Ethernet and WLAN interfaces and instead creates a single virtual interface that has a single IP and MAC address assigned to it. The handoff mechanism introduced in [37] has been simulated successfully and it should allow passengers to be mobile while using the networks on board trains.

\section{Addressing Issues}

Thus far we have presented a reference architecture for Internet access on trains as well as a discussion of handoff issues. However, we also need to account for the network topology and addresses on the train-based network. Network topology on board trains changes constantly [19], hence, there is a need to create a robust management infrastructure that will establish and maintain connectivity on the train while providing logical and IP addressing services [19]. Verstichel et al. [19] propose a connectivity management platform that uses the Train Communication Network standard (TCN) [7], an adapted Dynamic Host Configuration Protocol (DHCP) [38], and Network Address Translation (NAT) [39] to link the devices in a coach-level network into one network across the entire train. Addresses are statically assigned in the coach-level network and Network Address Translation is used to enable communication throughout the train.

\footnotetext{
${ }^{4}$ Note that [21] only studied handoffs between satellite and HSDPA; however, we expect similar results for other cellular-based systems.
} 


\section{INITIAL CONCEPTS}

In this section we provide an overview of some of the initial concepts that have guided deployment of broadband Internet on trains. We also examine the FAMOUS architecture, which was developed to provide Internet access to FAst MOving USers.

Due to the mobility of trains, Internet access can be provided on them only by use of wireless links. Correia and Prasad [40] present some of the technical challenges involved in providing wireless broadband services. The reader is referred to [40] for a more complete treatment of the important attributes of a wireless broadband system. References [34] and [41] address how to provide broadband communications to fast moving users. In 2001 Gavrilovich [34] argued that a large number of small cells operating at high frequencies was the most economical and practical infrastructure for providing wireless broadband access to many users. In Gavrilovich's model, these small cells were provided by moving base stations that travel along a track beside the roadway. The moving base stations were then linked to fixed base stations using wireless links. The fixed base stations were uniformly distributed along the roadway and were also interspersed with the mobile base stations. This combination of mobile and stationary base stations allowed the realization of broadband wireless communications while also yielding fewer handoffs due to the mobile base stations [34]. However, a moving base station may not be practical.

An architecture for providing communications and entertainment aboard a high-speed public transport system is proposed in [41]. This architecture is composed of the following components:

- A mobile subsystem that consists of a mobile subnetwork, access to an infrastructure network, and a mobility management component. The mobile subsystem is analogous to the access network in this paper. However, the mobile subsystem does not include any of the wireless communication technologies incorporated at the access network in the architecture presented here.

- A wireless transport subsystem that handles radio transmission between the mobile subsystem and the infrastructure network. The wireless transport subsystem is analogous to the wireless communication technologies found in the access network of Fig. 2.

- A land subsystem consisting of an infrastructure network and a network management component. The land subsystem is analogous to the aggregation network and the service providers' core networks.

In addition, Lin and Chang [41] argue that the link between the passenger device and the base station can be provided by IEEE 802.11, Bluetooth, or one of the Third Generation (3G) wireless standards. As we have seen already, WiMaxwhich is one of the $4 \mathrm{G}$ wireless standards-has been chosen in one deployment [4], [13], to provide the link between the train and a terrestrial network, while Wi-Fi has been chosen to provide the link between the passenger terminal and the train network. Finally, [41] also notes that for a train, the cell planning problem reduces to a one-dimensional problem, which should greatly facilitate frequency planning.

\section{A. FAMOUS Architecture and Its Extensions}

In this subsection we examine work done on the FAMOUS architecture; an architecture designed to support broadband Internet access for FAst MOving USers. All of this work ([5], [8], [19], [21], [23], [33], [37], [42], and [43]) was conducted by researchers in Belgium.

In the FAMOUS architecture, users do not connect directly to the base stations in the access network; instead, the entire train has a single connection to the access network. This connection is then shared amongst all the users on the train. The FAMOUS architecture assumes that seamless connectivity is not guaranteed for users in fast moving vehicles; instead they will hop from one access gateway (AGW) to the next [8]. Within the aggregation network, VLANs are used to group the different base stations in an access network that satisfy a given train's traffic demands [8]. Another component of this architecture is the service gateway, where connections are made between service providers and the aggregation network.

1) Aggregation Network Design: In [8] and subsequent papers ([23], [42], [43]), Ethernet is chosen for the aggregation network since it is simple, cost-effective and bandwidth flexible. In spite of Ethernet's advantages, it requires some modifications to support fast moving users such as:

- The rapid depletion of VLAN databases in Ethernet switches [43].

- A mechanism for fast recovery from link failures in the aggregation network [43].

- A mechanism to optimize the use of network resources, determine paths for dynamic tunnels in an aggregation network, and minimize the impact of packet loss and packet reordering when designing an aggregation network [42].

Solutions to all of these issues are found in [42] and [43]. The first issue is addressed by developing a protocol that allows for the separate distribution of traffic reservation parameters and VLANs to Ethernet switch hardware [43]. Fast recovery from link failures is provided by monitoring link status through examination of incoming and outgoing packets at a given switch [43]. The last problem is addressed by routing scheme choice [42].

The hierarchical wired Ethernet aggregation network can be combined with Ethernet-based wireless access networks for providing broadband Internet access [23]. In this case, there is a single WiMax base station per access network that is linked to the aggregation network via an Ethernet link. Packet loss is reduced if tunnels nearer the train are set up when a train announces its presence at a given access gateway, while tunnels in the higher parts of the network are set up using location information.

\section{TAxonomy of Architectures by AcCess NETWORK TECHNOLOGY}

In this section we provide a description of some technologies that have been proposed as options to provide broadband 
Internet access to fast moving users. We examine radio-overfiber, leaky-coaxial cable-based, IEEE 802.11-based, satellitebased, WiMax-based, and high-altitude platforms. We also examine architectures based on emerging standards.

\section{A. Radio-over-Fiber}

In 2007 Lannoo et al. [5] proposed extensions to Gavrilovich's [34] moving base stations model. Lannoo et al. [5] argue, just as in [8], that frequent handoffs greatly reduce the bandwidth available to fast moving users. Consequently, they propose using radio-over-fiber, as suggested in [8], to feed base stations along the rail track. Unlike Gavrilovich's model there are no moving base stations; instead there is a fiber-fed distributed antenna network. These distributed antennas are located along the railroad tracks, and they are called remote antenna units (RAU) (These correspond to the base stations in Fig. 2.). The remote antenna units are supervised by one control station via an optical ring network. For communications from the access network to the train, data is modulated at the control station and sent optically to each remote antenna unit using wavelength division multiplexing, i.e., each RAU has a unique wavelength for communications. The remote antenna unit will convert the optical signal to radio waves and transmit to the train. For communications from the train to the access network, the data will be captured by the remote antenna unit closest to the train. In order to reduce handoff times for the train access terminal, Lannoo et al. [5] propose using "moving cells," i.e., a cell pattern that is constantly reconfigured at the same speed as the train so that the train access terminal communicates on the same frequency during a trip. For a more complete treatment of Lannoo's moving cell concept, please consult [5]. Fig. 3 presents a reference architecture for the radio-over-fiber deployment.

\section{B. Leaky Coaxial Cable-based Architecture}

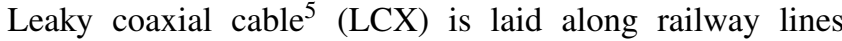
in Japan for radio communications on trains [46]. Ishizu et al. [47] observed in 2007 that new data services, such as broadband Internet and video, can be provided to passengers by using a new frequency band in the leaky coaxial cable. To support these data services, the system has to carry out seamless handoffs between leaky coaxial cable segments at high speeds. Ishizu et al. [47] propose an architecture for communications on "bullet trains" that consists of a base station with an Ethernet interface and mobile devices. Testbed results indicated that data rates of up to $768 \mathrm{kbps}$ could be achieved using LCX. The proposed architecture for Internet access on trains uses an Ethernet extension called Mobile Ethernet, which allows switches to learn paths and suppress unnecessary broadcasts once paths are learned. Each LCX transceiver has a transmission range of $17.3 \mathrm{~km}$ and about

\footnotetext{
${ }^{5}$ These are coaxial cables with slits cut in the jacket so that the radio waves can "leak out." These cables are used in places where electromagnetic waves cannot reach, such as: along railway tracks, tunnels, mines, and underground malls. LCX cable has been optimized for use in the $75-900 \mathrm{MHz}$ as well as the $800 \mathrm{MHz}$ to $2.6 \mathrm{GHz}$ bands [44]. Research has also developed a " $2.4 \mathrm{GHz}$ frequency band leaky coaxial cable for wireless network access" [45].
}

62 of these transceivers are needed to cover all of Japan's "bullet train" network. Assuming full utilization of each of the LCX transceivers, a gateway node between the aggregation network will need to support a peak data rate of $48 \mathrm{Mbps}$ (768 kbps $\times 62$ ). On board each train is a Mobile Bridge (MB) that has interfaces for different types of communication technologies, such as IEEE 802.11, IEEE 802.16, and an LCX mobile device. The LCX mobile device in the architecture addresses handoffs by detecting new LCX base stations and transmitting beacons in the aggregation network that update the forwarding tables for the mobile bridge in the aggregation network. Reference [47] concludes by noting that a testbed is being developed to test this architecture.

\section{IEEE 802.11-based Architectures}

Aboard trains, IEEE 802.11 can be used to: link all the railcars on the train into a computer network [48], provide Internet access to passengers [14], and connect a stationary train to the Internet [37]. In 2003 Bianchi et al. [48] argued that it may be expensive to wire a train for network access. In addition, [48] stated that rewiring may be needed every time the train is reconfigured. In the basic architecture presented in [48], the train is connected to the Internet through a "train server"- the train server is analogous to the train access terminal in Fig. 1.

Bianchi et al. [48] proposed two topologies, based on IEEE 802.11 [20], for constructing the computer network aboard the train. In the first topology, the railcars are linked into a network using IEEE 802.11 access points with antennas on the outside of each railcar, i.e., in this case, the gateways shown in Fig. 1 are IEEE 802.11 access points. In order to minimize interference between adjacent access points, Bianchi et al. [48] state that directional antennas should be used in this deployment. Furthermore, channels should be chosen on each access point, such that neighboring access points do not interfere with each other. Additional gains in performance may be achieved by using IEEE 802.11a [20] for the wireless network between railcars, and IEEE 802.11b [20] within the rail car. These technology choices imply that the computer network on the outside of the train would not interfere with that inside the railcars. An alternative topology for the network aboard the train arranges the access points in each railcar such that each access point serves as a client station for the access point in the previous car, while also serving as an access point for all the stations within its car. In other words, given train cars 1 and 2: the access point in car 2 serves as a client (station) of the access point in car 1, while also serving as the host (access point) for all stations within car 2. Since an access point may not transmit and receive simultaneously, this topology requires that each access point possess two interface cards- one for transmitting and the other for receiving. Bianchi et al. [48] conclude by noting that their proposed topologies need to be tested in a real-world deployment to assess the impact of interference. 


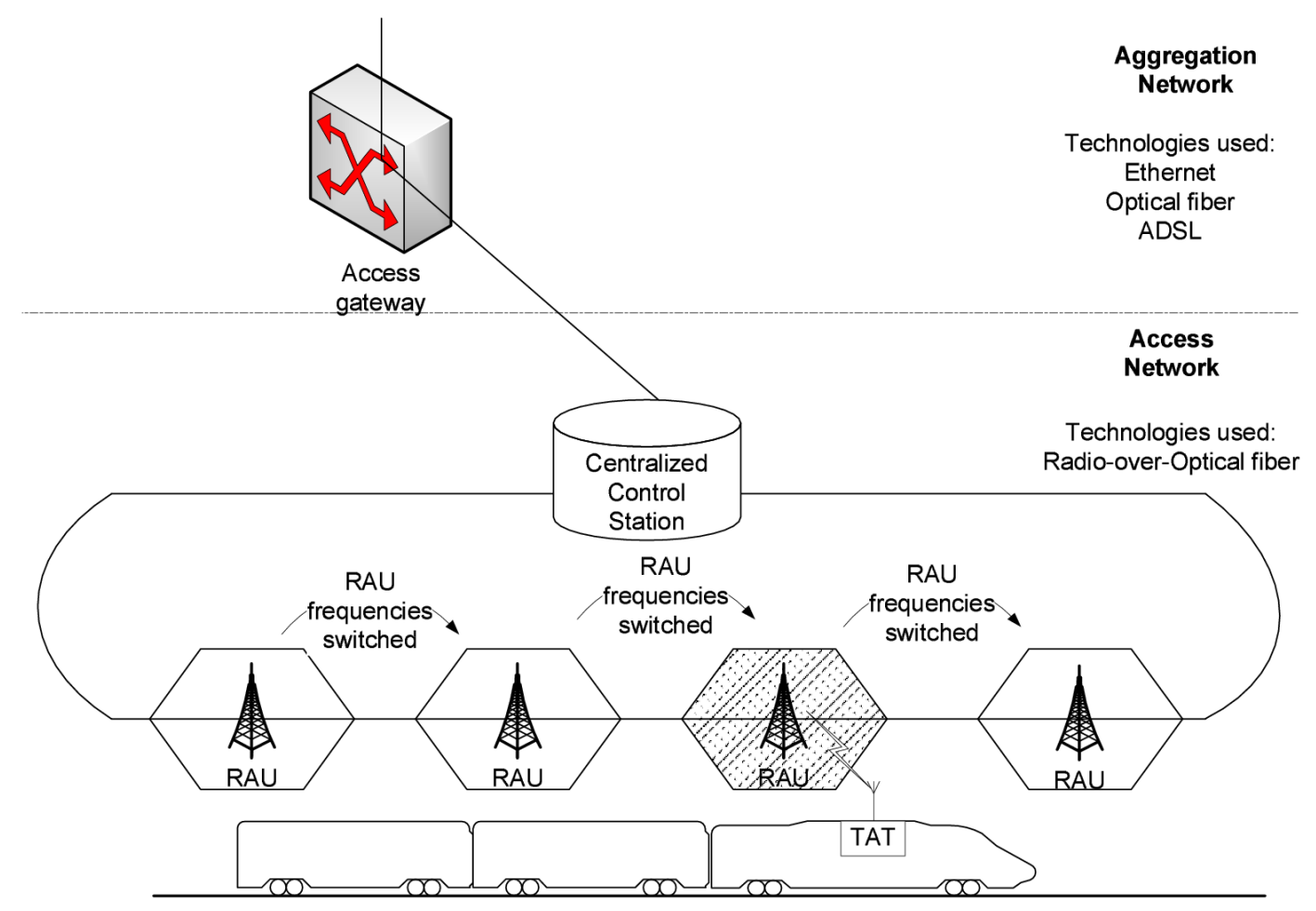

Fig. 3. Reference Architecture for Internet Access on Trains using Radio-over-Fiber, based on [5]

\section{Satellite-based Architectures}

Trains may be connected to the Internet via a satellite ${ }^{6}$ link [49]. One proposed architecture has been developed by ACCORDE, a company specializing in developing satellite RF equipment. Their architecture consists of communications, pointing, and distribution subsystems. The communications subsystem consists of an antenna, a satellite transmitter, and a modem (same as the train access terminal in Fig. 2). The pointing system performs satellite acquisition and tracking, while the distribution system uses optical fiber links to distribute the signal between the modem and each of the cars on the train. Within each car is an IEEE 802.11 or IEEE 802.16 access point. It should be noted that emerging technologies such as multi-beam lens antennas [50] may lead to improvements in the quality of the satellite signals received on trains.

\section{E. WiMax-based Architectures}

In 2008 Aguado et al. [51] presented a network architecture based on WiMax for use in railway environments. This architecture can also be used for railway signaling. WiMax can be considered for communications in railway contexts because it is claimed that the technology can provide mobility support at speeds up to $500 \mathrm{~km} / \mathrm{h}$ [51]. In addition, WiMax also provides QoS support.

One emerging trend in railways is the use of broadband wireless communications to control trains [51]. The communications between the train and the operations center can be

\footnotetext{
${ }^{6}$ It should be noted that trains using satellite links for Internet access typically use other technologies as "gap fillers" for areas where satellite coverage is limited.
}

used to enable safer railway operations. Aguado et al. [51] proposed an architecture for train signaling that consists of a train network, a trackside to train network, and the wireless backbone network. The train network is similar to the coach level network from Fig. 1, while the trackside to train network is analogous to the access network in Fig. 2. The coach network contains a WiMax node that also has Ethernet and IEEE 802.11 connections. The Ethernet connections are used to link all the carriages on the train into a network, while the IEEE 802.11 connections are used to provide connections to customers' laptops. The access network consists of regularly spaced WiMax nodes along the trackside. These nodes have two interfaces: one interface for connecting to the WiMax node on the train, and the other for connecting to WiMax nodes in the backbone network. Finally, the wireless backbone network is analogous to the aggregation network in Fig. 2. It consists of WiMax nodes each having three interfaces. Two interfaces are used for connecting to other nodes in the backbone network, while the other interface connects to nodes in the wayside to train network. Simulation results show that this network architecture can satisfy European Union requirements on endto-end delay in railway communication networks.

Kumar et al. [52] introduced an architecture called SWiFT (Seamless Wireless Internet for Fast Trains) in 2008. This architecture consists of IEEE 802.11e [20] access points within train carriages for the on-train network, IEEE $802.16 \mathrm{~m}$ base stations at the trackside for the access network, and an optical backbone (aggregation network) for linking the IEEE $802.16 \mathrm{~m}$ base stations to the global Internet. Kumar et al. [52] argue that this architecture is viable because customers can continue 
using their access terminals. Furthermore, Doppler effects for customers are reduced since the IEEE 802.11 access point is within the train carriage, while handoffs are simplified since the train appears as a single access terminal to the IEEE 802.16 network. The proposed architecture is used in conjunction with the proposed IEEE 802.21 standard [53] for smart handoffs. Simulation results show that by using triggers that predict Layer 2 handoffs, one can reduce the number of packets lost during a handoff [52].

\section{F. Architectures Based on Emerging Standards}

Most of the papers we have seen thus far use existing radio technologies, such as IEEE 802.16 [17] or cellular technologies. In 2004, Zou et al. [27] deviated from most of the previous work, and called for using IEEE 802.20 [18], which is technology under development, in the access network to provide broadband Internet access for trains. IEEE 802.20 is chosen because existing $3 \mathrm{G}$ technologies do not offer sufficiently high data rates to support many users on a high-speed train. IEEE 802.20 , on the other hand, is being designed to support data delivery at high bit rates to vehicles travelling at up to $250 \mathrm{~km} / \mathrm{h}$, while using the wireless spectrum efficiently [18]. As in many of the other systems reviewed thus far, Zou et al. [27] use an IEEE 802.11 WLAN on board the train to provide Internet access to passengers. In order to allow for smooth handoffs between base stations, they call for the train access terminal to make two IEEE 802.20 connections to two different base stations. However, the train would maintain a single IP address, using Mobile IP, throughout its journey. Furthermore, they argue that since the train's schedule is known, handoff instances should be handled by a Predictive Pre-handover ( $\mathrm{PPH})$ algorithm that would precompute the routes needed after a handoff. The access node on the train would actively monitor the received signal strength from IEEE 802.20 stations, and it would trigger a handoff whenever the received signal strength from the new station exceeds that of its current base station [27].

\section{G. High-Altitude Platforms for Internet Access}

With the exception of the system proposing the radioover-fiber methods for Internet access on trains, hitherto all the systems that we have studied examine communication protocols for providing Internet access. White and Zakharov [54], on the other hand, deal strictly with physical layer issues. They argue that high-altitude platforms, such as airplanes and airships at stratospheric altitudes, are a less costly yet feasible method of providing Internet access to trains. Digital Signal Processing (DSP) algorithms for tracking high-altitude platforms are presented in [54]. The algorithms' purpose is to estimate the direction of arrival (DOA) for signals transmitted from a high-altitude platform (HAP) to a train. Some of the methods applied for DOA estimation include Spectral-based [54] and Polynomial-based [54] techniques. An Extended Kalman Filter (EKF) is used to track the train location, while beam forming is used on the satellite uplink. Finally, [54] shows that EKF can track slow variations in train velocity and account for sudden HAP motion. Null steering (beam steering) is also shown to be advantageous in HAP-train data communications.

\section{H. Internet Access through Direct Connectivity with Customer Terminals}

It is also becoming more common for laptops to ship with 3G modems built-in. Furthermore, train passengers are able to get Internet access by connecting 3G-capable telephones to their laptops. Since each user connects directly to the access network there is no train access terminal in this case. Sauter [24] describes tests conducted by connecting an HSDPA terminal directly to a communications network outside the train as he travelled from Paris to Frankfurt on a German Intercity Express high-speed train. Peak download speeds of about $1.5 \mathrm{Mbps}$ with average download rates of $850 \mathrm{kbps}$ were observed during the test [24]. Sauter concludes by arguing that dedicated $3 \mathrm{G}$ coverage along railway tracks would give a "smooth user experience" without any train access terminals.

Table II compares the access technologies presented in this section. The cell sizes for the access technologies presented above are different, thus, the Frequency of Handoff column in Table II gives an indication as to how often the train access terminal will switch from one base station to the next at typical train speeds, i.e., $100+\mathrm{km} / \mathrm{h}$.

\section{Testbed Results}

Thus far we have reviewed the reference architecture, initial concepts underpinning broadband Internet deployment on trains, and a taxonomy of access network technologies. In this section we review results from testbed implementations of Internet access on trains. The transition from the more theoretical to prototypes and deployment begins in [56] and [57]. In 2004 Sivchenko et al. [56] presented simulation results showing that Internet traffic performance on high-speed trains decreases as the number of users increases, which is an expected result. The performance of several existing radio technologies with respect to data rates experienced on fast moving trains is investigated in [57]. Gaspard and Zimmermann [57] evaluated the relationship between throughput as a function of Doppler shift (speed) in 2005. This investigation was carried out in two phases: in the first stage, a channel sounder was used to take channel measurements for different placements of a mobile receiver, while the mobile transmitter was moved along the track. In the next stage, different access network radio technologies were evaluated using a hardware emulation of the channel characteristics. The experiments evaluated how throughput would vary for a channel between a trackside transmitter and a receiver on board a train. Experimental results indicate that:

- TCP/IP throughput of a UMTS-FDD downlink does not vary much with receiver input power; however, it is relatively low, i.e., $\sim 0.06-0.35$ Mbps.

- At $300 \mathrm{~km} / \mathrm{h}, \mathrm{TCP} / \mathrm{IP}$ throughput of an IEEE $802.11 \mathrm{~b}$ link between a trackside transmitter and a receiver on the train varies with receiver input power due to multipath channels. It should be noted that IEEE $802.11 \mathrm{~b}$ provides high data rates under the measurement conditions. In 
TABLE II

COMPARISON OF ACCESS TECHNOLOGIES

\begin{tabular}{|l||l||l||l||l|}
\hline $\begin{array}{l}\text { Access Network } \\
\text { Technology }\end{array}$ & Data Rates & $\begin{array}{l}\text { Frequency of } \\
\text { Handoff }\end{array}$ & Technology Maturity & Comments \\
\hline IEEE 802.11 & Up to 54 Mbps & High & Mature & $\begin{array}{l}\text { Tested in the access network of [55] as a gap- } \\
\text { filler. Frequently used for the link between } \\
\text { customer terminals and the access point in } \\
\text { each car. }\end{array}$ \\
\hline WiMax & Up to 104 Mbps [17] & Medium & $\begin{array}{l}\text { Mature. Other draft standards } \\
\text { are being added to improve } \\
\text { performance at high speeds. }\end{array}$ & $\begin{array}{l}\text { Used by Utah Transit Authority and South- } \\
\text { ern Trains [13]-[15]. }\end{array}$ \\
\hline GPRS & Up to 171 kbps & Medium & Mature & $\begin{array}{l}\text { Used by Southern Trains [13], [14]. } \\
\text { press track from Paris to Frankfurt [24]. }\end{array}$ \\
\hline HSDPA & Up to 14.4 Mbps & Medium & Mature & Reported in [26]. \\
\hline FLASH-OFDM & $\begin{array}{l}\text { Up to 5.3 Mbps } \\
\text { (download), Up to } \\
1.8 \text { Mbps (upload) }\end{array}$ & Medium & Mature & Used by Thalys and SNCF trains [14], [55]. \\
\hline Satellite & $\begin{array}{l}512 \mathrm{kbps} \text { (upload), } \\
2 \mathrm{Mbps} \text { (download) }\end{array}$ & Low & Mature & Deployed in Japan [47]. \\
\hline Leaky coaxial cable & Up to 768 kbps & High & Mature & Not yet deployed. Proposed in [5]. \\
\hline Radio-over-fiber & $\begin{array}{l}\text { Targeting } \\
5 \text { Gbps }\end{array}$ & High & Immature & Not yet deployed. Proposed in [27]. \\
\hline IEEE 802.20 & Over 1 Mbps & Medium & Standards being drafted \\
\hline
\end{tabular}

addition, the authors state that one would need several access points along the track to have good coverage.

- The IEEE 802.16 system evaluated in [57] was not suited for high-speed trains since TCP/IP throughput decreased sharply with increasing speed. However, the authors note that the amendments to the IEEE 802.16e standard for mobility should enhance the performance of the IEEE 802.16 system.

Ceprani and Schena [58] presented implementation details on their Fast Internet for Fast Train Hosts (FIFTH) project in 2004. The FIFTH architecture consists of Mobile Train Terminal Prototype (MTTP) and FIFTH Access Network Infrastructure (FANI) modules. The MTTP is composed of a Satellite Access Terminal (SAT), which uses the $\mathrm{Ku}$ band to provide satellite access for the train, and the Train UserLocal Area Network (TU-LAN), which constitutes the LAN on board the train. The satellite access terminal is analogous to the train access terminal in Fig. 1, while the Train User-Local Area Network is akin to the rest of the computer network shown in Fig. 1. The antenna for the SAT is adjusted by a Navigation and Tracking Unit during a trip to optimize reception conditions. The TU-LAN consists of a coach LAN (within a train car) and a train LAN (between cars on the train). The TU-LAN is implemented by using Ethernet connections between train cars, as well as Ethernet connections and IEEE 802.11 links for passengers to use. Unfortunately, additional details are not available on what bit rates were seen during the trial.

Lomas [55] discusses a 2008 deployment of Internet access to three SNCF trains travelling at speeds of up to $320 \mathrm{~km} / \mathrm{h}$ $(88.8 \mathrm{~m} / \mathrm{s})$ across France. The trains use a combination of satellite and Wi-Fi links for Internet access. The train access terminal uses an Eutelsat satellite and then switches over to a Wi-Fi relay when the antenna on the train loses line of sight with the satellite, for example, at stations or in tunnels. The system provides speeds of $512 \mathrm{kbps}$ and $2 \mathrm{Mbps}$ for upload and download, respectively. The train company, SNCF states that there is a traffic optimizer on the train that gives priority to passenger flows over train maintenance flows [59]. Lomas [55] adds that the SNCF system can only support up to 50 of 375 passengers on the train. Hence, if more passengers want to get Internet access, the system will need to be upgraded.

A lot of the work coming from North America is experimental, given the lack of widespread Internet access on board trains. One example of some experimental work comes from the University of Nebraska, where Hempel et al. [25] deployed a wireless testbed for IEEE 802.11 along a train track in 2006. In this testbed, IEEE 802.11 access points were placed along the tracks with line of sight paths to neighboring access points. This arrangement allowed for seamless IEEE 802.11 coverage along the tracks. IEEE 802.11a channels were used to provide backhaul links between the testbed access points, while IEEE $802.11 \mathrm{~b}$ was used to provide wireless Internet connectivity to the train car used in the tests. Results from the testbed showed that IEEE $802.11 \mathrm{~b}$ could support data rates of up to $11 \mathrm{Mbps}$; however, IEEE $802.11 \mathrm{~b}$ was also subject to interference from passing trains. Additional test results showed that train velocity does not appear to have a significant effect on the throughput experienced by the node on board the train. The conclusion from this paper is that while it is feasible to deploy IEEE 802.11 along the train track, IEEE 802.11 has a limited coverage area; therefore, such a deployment would be expensive [25].

Most of the work we have reviewed in this paper has discussed providing Internet access to passengers on a train. However, a train operator might also like to collect operational data from its trains. Edwards et al. [2] discuss just such a scheme that allows for controlling and monitoring various sensors and supervision modules on a freight train. This scheme uses IEEE 802.11b for intratrain communications to allow for braking, coupling and uncoupling, etc. This scheme uses a Controller Area Network (CAN) bus to collect data from sensors on board the train. The data is then coupled with GPS information and reported to a web server via a CDMAbased transmitter. In this case, the train access terminal is a 
1xRTT radio, whereas the links between the cars are IEEE 802.11b links, unlike the wired links shown in Fig. 1.

\section{IMPLEMENTATION EFFORTS}

In the previous section we reviewed results from testbed implementations of Internet access to trains. In this section we look at how those ideas have been implemented in Europe and North America. As we mentioned in Section I, broadband Internet access is increasingly becoming available on trains in Europe. In Europe, the preponderant demand for Internet access is from passengers, while in North America, train traffic is dominated by freight [60]. As a result, efforts to carry out communications from trains have evolved in slightly different directions on these two continents due to market forces. We review the implementation efforts in Europe and North America separately, since conclusions drawn from one continent might not necessarily apply to the other. Furthermore, implementation efforts in Europe are much more advanced than those in North America. In 2007, zu Hörste [61] observed that railway operators are moving away from proprietary communications systems solutions to commercial off-the-shelf (COTS) solutions to reduce cost while improving bandwidth and reliability. In this section we will see implementations based on open standards such as WiMax and cellular technologies-a trend that appears to validate zu Hörste's observation.

\section{A. Implementation in Europe}

One of the earliest accounts of Internet access on trains comes from the Railway Open System Interconnection Network (ROSIN) project. In 1999, Fabri et al. [62] presented a report on a web-based tool deployed to a train to allow maintenance staff to supervise railroad equipment using a GSM connection between the train and an operations center. Aboard the train, the railcars were linked into a network using the Train Communication Network $\left(\mathrm{TCN}^{7}\right)$ standard [63]. Unfortunately, reference [62] does not provide any additional details on the bit rates seen during the trial or the network topology.

Conti [14] provides a contemporary (2005) view of the implementation of Internet access on trains in Europe. In his paper he argues that telecommunications operators have offered Internet access to passengers using GPRS [64] or $3 \mathrm{G}$ wireless cards; however, this is not sufficient for most users. Furthermore, he states that there is now agreement that Internet access should be provided on board trains using IEEE 802.11 access points within the train; however, there is not much agreement on how to connect moving trains to the Internet backbone. In the United Kingdom, GNER trains use a combination of satellite and cellular links to provide a backhaul link from the train. Therefore, the train access

\footnotetext{
${ }^{7}$ The TCN specification consists of a train bus and a vehicle bus. The train bus can self-configure by connecting a new node (railcar) to the network and dynamically assigning it a new address The vehicle bus is optimized to handle small packets originating from a large number of devices. The train bus and the vehicle bus are connected through a gateway, which allows for exchange of data between devices in the same railcar, or in two different train cars. The TCN can also be linked to the Internet by means of a radio link between the train and a ground station.
}

terminal in this instance supports both satellite and cellular technologies. The Internet connection is shared with all cars on the train using the train's lighting circuit; this implies that the topology of the computer network on the train is not radically different from that shown in Fig. 1. Unfortunately, additional details are not available on how the wired portion of the network aboard the train operates. GNER's system favors satellite access for the backhaul link, but when the train enters a tunnel, the system automatically switches over to GPRS (The technical details of how this switch is accomplished are not available in [14].). For redundancy purposes, the train connects to base stations from two different mobile carriers. In addition, up to six parallel cellular phone links are established for redundancy purposes when the train passes through a tunnel. It is worth noting that this same technology is also used by the Swedish train operator, SJ, to provide Internet access [14].

Conti [14] discusses Southern Trains' efforts to provide Internet access on its trains along the $96 \mathrm{~km}$ London-Brighton route using WiMax [4]. It is interesting to note that this system does not use any of the enhancements found in IEEE 802.16e, which is designed for mobile access. Instead, this system uses a draft implementation of IEEE 802.16 [13]. T-Mobile and Nomad Digital collaborated on the implementation of this venture; however, it is now operated by T-Mobile. In addition to the pre-WiMax standard, GPRS and $3 \mathrm{G}$ technologies are also used for robustness with each train having three GPRS modems for redundancy [13]. As of 2005 there were 37 WiMax base stations deployed along the track, with plans to install up to 60 base stations [13]. The base stations operated in the 5.4-5.8 GHz band with a $1 \mathrm{~W}$ maximum power output [65]. Each base station is equipped with a 2 Mbps ADSL link to the Internet [13], even though each base station could achieve data rates of up to $32 \mathrm{Mbps}$ for both the uplink and the downlink wireless channels [14]. In Southern Trains' implementation, the train access terminal consists of a server with support for WiMax and GPRS technologies. The architecture of the in-train network is akin to that shown in Fig. 1, with passengers connecting to the in-train network using an IEEE 802.11b link [13]. Finally, the access network in this case uses WiMax and GPRS [13], while the aggregation network uses ADSL [13].

As we have already seen, satellite links can also be used for Internet access on trains. By 2005, a European train company, Thalys, [14] was using a bidirectional satellite link, designed by $21 \mathrm{Net}$, and operating in the Ku-band to support link speeds of up to $2 \mathrm{Mbps}$; i.e., the train access terminal only supports satellite links. The downside of relying on satellite links is that operational costs are probably higher than for links that rely on either WiMax or 3G technologies [14]. By 2008 Thalys claimed that all of its trains provided broadband Internet access. Thalys has routes from Marseille to Paris, Paris to Brussels, Brussels to Amsterdam, and Brussels to Cologne.

Echensperger [26] discusses work done by T-Mobile in Germany to bring Internet access to Intercity Express trains. He discusses the Railnet effort, which aims to provide WLAN access on board trains while also providing a broadband radio connection between the train and the land side. The Railnet system uses a Central Train Unit to control traffic and store 
onboard content, several antennas to maintain the train to base station link, an IEEE 802.11 network to link the rail cars into a train level network, and IEEE 802.11 access points on board the train for passenger access. The onboard network for the Railnet effort is very similar to that shown in Fig. 1, except that there are no wired links between the railcars. Instead, there are IEEE 802.11 links between the cars. The train access terminal in this case supports T-Mobile's access technology (Unfortunately, technical details on the access technology are not available in [26].). Since T-Mobile (the service provider) owns its network, and also provides service on board the train, there is not much of a distinction between the access and aggregation networks in this case. It is worth noting that FLASH-OFDM has also been evaluated in the course of the Railnet effort, and its throughput has been found to be nearly independent of velocity [26]. By 2009, broadband Internet service was available on routes between Dortmund and Cologne, Cologne and Frankfurt, Frankfurt and Munich, and Frankfurt and Hamburg.

\section{B. Implementation in North America}

As previously mentioned, rail transportation in North America and Europe have very different characteristics. Consequently, broadband Internet deployment to trains on those continents has evolved differently. In fact, it could even be argued that these deployments are in their infancy in North America. However, there are some efforts underway for North America. For example, Conti [14] points out that PointShot Wireless has worked on initial deployments with Canada's VIA Rail and California's Altamont Commuter Express and Capitol Corridor operators.

In 2008, Nomad Digital collaborated with the Utah Transit Authority (UTA) and Wasatch Electric to provide a wireless broadband connection on a $64 \mathrm{~km}$ long commuter line between Ogden and Salt Lake City. In this case the access network consists of WiMax radios from Redline Communications. On board the train, passengers get Internet access from a free Wi-Fi connection [15]. The onboard network for this rail deployment is very similar to that shown in Fig. 1, while in this instance the train access terminal supports WiMax. Unlike any of the examples seen thus far, the aggregation network in this instance is composed of fiber optic links, some of which run trackside [15].

\section{Business Models And A FeAsibility Study}

As we have seen in previous sections, broadband Internet access is increasingly being deployed to trains. However, for us to see more widespread deployments, train operators would have to be convinced of the business advantages of such a deployment. In this section we present different business models for paying for Internet service on trains.

One of the earliest business models developed studied deploying Internet access to intercity trains in California [30]. In developing this model, the authors say that the provision of Internet access on trains would likely lead to an increase in ridership on intercity trains. The train operators, on the other hand, could collect revenue from this service either by applying "per use or time charges, subscription fees," or by negotiating an arrangement with a third party to pay for the service through advertising, or sponsorship, or an increase in ridership [30]. In the case of California trains, the authors present two business models for providing Internet access:

- Option 1 is a conservative model that uses satellite and cellular networks for backhaul, with an IEEE 802.11 access network on the train. This option has a low operational cost with low bandwidth and a high operational cost with high bandwidth, but it generally results in low revenue for the train operator. This option is aimed at capturing mobile Internet users on trains in a conservative manner.

- Option 2 uses WiMax for backhaul access with an onboard Wi-Fi network, but it has a high initial cost (due to the cost of deploying WiMax antennas) with low operational costs. Kanafani et al. [30] state that this model should result in high revenue for the train operator, and that it should help capture mobile Internet users as the market grows.

The next two business models were developed for use in Europe. Using data from Belgian railways, Lannoo et al. [66] present business models that investigate the possibilities and economic viability of providing Internet access on trains. Recall that these researchers are part of the same group that proposed the FAMOUS architecture. As in previous work, they argue that broadband Internet access on trains can be provided by using an in-train network and a network between the train and the service provider for Internet access. For the backhaul network, trains can use cellular networking technologies such as GPRS, UMTS (HSDPA), or wireless networking technologies such as Wi-Fi, WiMax, FLASH-OFDM, or even a satellite networking standard, such as DVB-S/DVB-S2/DVBRCS. These backhaul networks can be classified as either incumbent networks, for example, GPRS, UMTS (HSDPA), or dedicated networks, such as, WiMax or FLASH-OFDM, or satellite networks. With incumbent networks the goal would be to provide Internet access on trains without making a major capital expenditure. The business model presented in [66] considers using incumbent networks until their capacity requirements are exceeded, then one can roll out a dedicated network. Satellite networks would only be used as gap fillers, i.e., in areas where the other networking standards do not provide adequate coverage, just as we saw in [14]. The analysis carried out in [66] assumes revenue schemes where either every passenger pays for Internet service, or only first class passengers get free Internet access, while all other passengers pay. Their analysis also includes the capital expenses required for deploying Internet service, as well as the operational costs required to maintain service. The model then presents results to show that train operators would realize a net profit if only first class passengers get free Internet access. Lannoo et al. [66] conclude by noting that using a combination of technologies is the best way to provide broadband Internet access to trains, and that in the particular case of Belgian railways it would be better to use a mix of WiMax and UMTS for Internet access [66]. 
More recently Riihimaki et al. [32] have studied Finnish railroads to determine the feasibility of deploying broadband Internet to trains. They argue that revenue from providing Internet service to train customers may come from the following sources:

- An increase in passenger volume, if a train operator offers free Internet access for passengers.

- An increase in the number of first class passengers, if first class passengers get free Internet access.

- Reduced personnel costs, if passengers who buy their tickets online get free onboard Internet access.

- Direct revenue, if train tickets and data connections are sold separately.

From the standpoint of the train operator, Internet access on trains could allow for more efficient train operations, e.g., allowing real-time traffic control, or more efficient staff who can verify passenger tickets in real-time.

Hitherto, we have focussed on Internet access to passengers, Riihimaki et al. [32] state that train operators shipping freight could use a broadband Internet connection to allow their customers to perform accurate cargo monitoring. In the case of the Finnish railroads, it is argued that the cost of building a network for Internet access from trains can be spread out over a period of time if the network is built in two or more phases, for example, by using GPRS or FLASH-OFDM in the first phase, and then using mobile WiMax in the second phase. Furthermore, in the case of WiMax, they show that the average revenue collected per user (passenger) and the cell range of the WiMax network are the most critical parameters influencing this technology's viability for Internet access on trains [32]. For example, their analysis is based on an estimated WiMax cell size of $5 \mathrm{~km}$. However, if this cell size is decreased by $10 \%$ then it becomes unprofitable to provide Internet access using WiMax [32].

Lundberg and Gunningberg [67] study the feasibility of using IEEE 802.11 networking equipment to provide Internet access for a train traveling at $200 \mathrm{~km} / \mathrm{h}$ between Uppsala and Stockholm. Here they observe that commercial solutions for providing Internet access on trains are available, but note that they are either limited or expensive. Furthermore, they observe that if IEEE 802.11 technology is used, the technology choice will depend on the possible impact of fading and related problems, such as the Doppler effect due to the train's motion [67].

Given that most of the train traffic in North America is freight traffic [60], possibly the best avenue for getting broadband Internet access on trains would be to forge some kind of partnership between the train companies and telecommunications companies. If the train operators can see a reduction in their insurance payments by allowing freight customers to gain visibility into their shipments or other gains in efficiency, then the long-term viability of broadband Internet on trains may be achieved in North America. In the case of the United States, Amtrak passengers can also benefit from a deployment of broadband Internet access to trains, and perhaps even more people can be lured to riding trains, resulting in lower greenhouse emissions.

\section{LESSONS LEARNED}

In the last section we presented a review of models that can be used to test the viability of broadband Internet access on trains. In this section we present a summary of some of the lessons that have been learned from broadband Internet deployments on trains.

- Most of the deployments that we have seen in this paper provide a single access terminal per train, and the connection(s) made by the access terminal is shared by all passengers on the train. Such an architecture prevents the mobile telephony provider from having to make handoffs for many users simultaneously.

- Rodriguez et al. [29] stated that an access terminal displays better performance if several technologies are combined. Except for the Thalys deployment, each of the systems discussed in Section VII combines several access technologies.

- Switched Ethernet may be used in a carrier-grade network to support fast moving users; however, extensions are needed to improve Ethernet's recovery from link failures. Optimization techniques can also be applied to determine paths for dynamic tunnels in the aggregation network while minimizing the impact of packet loss and packet reordering.

- Fourth-generation communication technologies, such as WiMax, have already been used in broadband Internet deployments to trains.

- A modified version of IEEE 802.11 has been used as a "gap filler" technology to provide Internet access to trains in areas where the train might not have a line of sight path to a satellite.

- It has been shown [57] that IEEE 802.11 provides high data rates at high speeds. However, except for the gapfiller case, IEEE 802.11 is typically not used in the access network because it costs too much to install sufficient access points at the trackside.

- While Lannoo et al. [5] have argued that satellite links are not suited for broadband Internet access to trains, we have seen two cases from Europe (Thalys and SNCF) that rely primarily on satellite links.

- Passengers are beginning to use 3G-capable hardware to connect to the cellular infrastructure directly from within trains [24]. This is in spite of Lannoo et al.'s [5] argument that a direct link between the passenger and a base station is subject "to high penetration losses because of the Faraday cage characteristics" of the railcar [5].

\section{CONClusion}

The availability of broadband Internet access on trains should prove to be a revenue source for operators. Previous studies from the United Kingdom show that train companies can attract more passengers if Wi-Fi access is made available [1]. In this paper, we have presented some of the initial approaches, current technologies, and future ideas, such as IEEE 802.20 and radio-over-fiber, related to Internet access on trains. We have also provided an account of implementation efforts for broadband Internet access on trains in Europe 
and North America. These efforts, particularly from Europe, show that broadband Internet access on trains is realizable. Furthermore, business models, developed to test the viability of Internet access on trains, show that broadband Internet access on trains is best realized by using a combination of access technologies. However, efficient operation requires proper system design. North America does not share the same rail traffic characteristics as Europe [60], and so broadband Internet access on North American trains is not as readily available. In North America, broadband Internet access on trains may be used for collecting operational data from trains, as well as freight monitoring. Future work could be to develop a business model for broadband Internet access on North American trains that takes into account the fact that North American rail traffic is dominated by freight. A good business model might serve to accelerate the deployment of broadband Internet access in North America.

\section{ACKNOWLEDGMENTS}

The authors would like to thank Y. Lewis and A. Francis for reading and commenting on previous versions of this paper. We would also like to thank the reviewers for their helpful comments.

\section{REFERENCES}

[1] BBC News. (2004, May 20) Wi-Fi May Tempt Travellers. News. BBC News. London, United Kingdom. [Online]. Available: http: //news.bbc.co.uk/2/hi/technology/3729583.stm

[2] M. C. Edwards et al., "Improving Freight Rail Safety with onboard Monitoring and Control Systems," in Proceedings of the 2005 ASME/IEEE Joint Rail Conference, Pueblo, CO, USA, Mar 2005, pp. $117-122$.

[3] BBC News. (2004, July 6) Rail Users Get Wi-Fi Net Access. News. BBC News. London, United Kingdom. [Online]. Available: http://news.bbc.co.uk/2/hi/uk_news/england/3868585.stm

[4] B. Wilson. (2005, Oct. 26) Rail Internet Access Picks Up Speed. News. BBC News. London, United Kingdom. [Online]. Available: http://news.bbc.co.uk/2/hi/business/4363196.stm

[5] B. Lannoo et al., "Radio-over-fiber-based Solution to Provide Broadband Internet Access to Train Passengers," Communications Magazine, IEEE, vol. 45 , no. 2 , pp. $56-62$, Feb. 2007.

[6] I. Beeby, "Demystifying Wireless Communications for Trains," Presented at the BWCS Train Communication Systems 2006, London, UK, June 2006.

[7] P. A. Laplante and F. C. Woolsey, "IEEE 1473: An Open-Source Communications Protocol For Railway Vehicles," IT Professional, vol. 5, no. 6, pp. 12-16, November/December 2003.

[8] F. De Greve et al., "FAMOUS: A Network Architecture for Delivering Multimedia Services to FAst MOving USers," Wireless Personal Communications, vol. 33, no. 3-4, pp. 281-304, 2005.

[9] G. Jeney et al., "Communications Challenges in the CelticBOSS Project," in 7th Int'l Conf. Next Generation Teletraffic and Wired/Wireless Advanced Networking, ser. Lecture Notes in Computer Science, Y. Koucheryavy et al., Eds., vol. 4712. Springer, 2007, pp. 431-442.

[10] I. Beeby, "The Future for Terrestrial Wireless Services for the next Five Years: Myths and Realities for WiFi on Trains," Presented at the BWCS Train Communication Systems 2007, London, UK, June 2007.

[11] Part 16: Air Interface for Fixed and Mobile Broadband Wireless Access Systems: Advanced Air Interface, Draft Standard, IEEE Working document 802.16m-09/0010r1a, Mar 2009.

[12] "Universal Mobile Telecommunications System (UMTS); LTE; Requirements for Evolved UTRA (E-UTRA) and Evolved UTRAN (EUTRAN)," ETSI, Sophia Antipolis, France, Tech. rpt TR 25.913, Jan 2009, version 8.0.0 Release 8.

[13] P. Judge. (2005, Apr. 3) $100 \mathrm{mph}$ WiMax hits the rails to Brighton. News. TechWorld. United Kingdom. [Online]. Available: http://www.techworld.com/mobility/features/index.cfm?FeatureID=1351
[14] J. P. Conti, "Hot Spots on Rails," Communications Engineer, vol. 3, no. 5, pp. 18-21, Oct./Nov. 2005.

[15] Nomad Digital. (2008, May 21) U.S. First for Nomad Digital: WiFi provided free for all rail passengers. Press Release. Nomad Digital. Newcastle, United Kingdom. [Online]. Available: http://www.uknomad. com/content.html?cm_id=1014\&action=press_details\&id=6

[16] M. Aguado et al., "Railway Signaling Systems and New Trends in Wireless Data Communication," in IEEE 62nd Vehicular Technology Conference, (VTC-2005-Fall), vol. 2, Sept., 2005, pp. 1333-1336.

[17] Air Interface for Fixed Broadband Wireless Access Systems, IEEE Std. 802.16, 2004

[18] Draft Standard for Mobile Broadband Wireless Access (MBWA), IEEE Draft Standard 802.20-D1, 2006.

[19] S. Verstichel et al., "On the Design of a Train Communication Management Platform," in Symposium on Communications and Vehicular Technology, Liège, Belgium, Nov. 2006, pp. 29-34.

[20] Wireless LAN Medium Access Control (MAC) and Physical Layer (PHY) Specifications, IEEE Std. 802.11, 2007.

[21] D. Pareit et al., "QoS-enabled Internet-on-train network architecture: inter-working by MMP-SCTP versus MIP," in 7th International Conference on ITS Telecommunications (ITST '07), Sophia Antipolis, France, June 2007, pp. 1-6.

[22] E. Perera et al., "Survey on Network Mobility Support," SIGMOBILE Mob. Comput. Commun. Rev., vol. 8, no. 2, pp. 7-19, 2004

[23] F. Van Quickenborne et al., "Managing Ethernet Aggregation Networks for Fast Moving Users," Communications Magazine, IEEE, vol. 44, no. 10 , pp. $78-85$, Oct. 2006

[24] M. Sauter. (2007, July 16) 3G and HSDPA Internet Access on a High Speed Train. Blog. [Online]. Available: http://mobilesociety.typepad. com/mobile_life/2007/07/hsdpa-internet-.html

[25] M. Hempel et al., "A Wireless Test Bed for Mobile 802.11 and Beyond," in IWCMC '06: Proc. 2006 Int'l Conf. Wireless Communications and Mobile Computing. Vancouver, BC, Canada: ACM, 2006, pp. 10031008.

[26] H. Echensperger, "Railnet: High-Speed Internet on High-Speed Trains," Presented at the IET Seminar: Broadband on Trains, London, United Kingdom, Feb. 2007

[27] F. Zou et al., "IEEE 802.20 Based Broadband Railroad Digital Network - The Infrastructure for M-Commerce on the Train," in The Fourth Int' Conf. Electronic Business - Shaping Business Strategy in a Networked World (ICEB), Beijing, China, 2004, pp. 771-776.

[28] F. De Greve et al., "Towards Ethernet-Based Wireless Mesh Networks for Fast Moving Users," in EUROMICRO '06: Proc. of the 32nd EUROMICRO Conf. Software Engineering and Advanced Applications. Dubrovnik, Croatia: IEEE Computer Society, Aug 2006, pp. 387-397.

[29] P. Rodriguez et al., "MAR: a Commuter Router Infrastructure for the Mobile Internet," in MobiSys '04: Proc. 2nd Int'l Conf. Mobile systems, applications, and services. Boston, MA, USA: ACM, 2004, pp. 217230.

[30] A. Kanafani et al., "California Trains Connected," University of California - Berkeley, Tech. Report UCB-ITS-PRR-2006-4, Apr. 2006.

[31] C. Perkins. (1996, Oct) IP Mobility Support. RFC 2002. [Online]. Available: http://www.ietf.org/rfe/rfc2002.txt

[32] V. Riihimaki et al., "Techno-economical Inspection of High-speed Internet Connection for Trains," IET Intelligent Transport Systems, vol. 2, no. 1 , pp. 27-37, Mar. 2008

[33] T. Van Leeuwen et al., "Broadband Wireless Communication in Vehicles," in FITCE 2003: 42nd European Telecommunications Congress, Berlin, Germany, Sep. 2003, pp. 77-82.

[34] C. D. Gavrilovich, "Broadband Communication on the Highways of Tomorrow," Communications Magazine, IEEE, vol. 39, no. 4, pp. 146154, Apr. 2001

[35] C. Huang and C. Tsai. (2006) Mobile Multi-path Transmission using SCTP. Internet draft. [Online]. Available: http://www.ietf.org/ internet-drafts/draft-huang-tsai-mmp-sctp-00.txt

[36] D. Mulvey, "HSPA," Communications Engineer, vol. 5, no. 1, pp. 38-41, February-March 2007

[37] B. Jooris et al., "Mobile Communication and Service Continuity in a Train Scenario," Presented at the 12th Symposium on Communications and Vehicular Technology in the BENELUX, Enschede, Netherlands, Nov 2005.

[38] R. Droms. (1997, Mar) Dynamic Host Configuration Protocol. RFC 2131. [Online]. Available: http://www.ietf.org/rfc/rfc2131.txt

[39] K. Egevang and P. Francis. (1994, May) The IP Network Address Translator (NAT). RFC 1631. [Online]. Available: http://www.ietf.org/ rfc/rfc1631.txt 
[40] L. M. Correia and R. Prasad, "An Overview of Wireless Broadband Communications," Communications Magazine, IEEE, vol. 35, no. 1, pp. 28-33, Jan. 1997.

[41] K. D. Lin and J. F. Chang, "Communications and Entertainment Onboard a High-speed Public Transport System," Wireless Communications Magazine, IEEE, vol. 9, no. 1, pp. 84-89, Feb. 2002.

[42] F. De Greve et al., "Cost-effective Ethernet Routing Schemes for Dynamic Environments," in GLOBECOM'05: IEEE Global Telecommunications Conference, vol. 2. St. Louis, MO, USA: IEEE, Nov 2005, pp. 1023-1028.

[43] _ "A New Carrier Grade Aggregation Network Model for Delivering Broadband Services to Fast Moving Users," International Journal of Communication Systems, vol. 20, no. 3, pp. 335-364, Mar. 2007.

[44] AFL Telecommunications. (2009, July 10) Coaxial Cable: Leaky Coaxial Cable (LCX). Marketing brochure. AFL Telecommunications LLC. [Online]. Available: http://www.afltele.com/products/fiber_optic_ cable/coax_cable/leaky_coax/

[45] M. Nakamura et al., "Development of a $300 \mathrm{~m} 2.4 \mathrm{GHz}$ Frequency Band Leaky Coaxial Cable for Wireless Network Access," in IEEE Radio and Wireless Symposium, Orlando, FL, Jan. 2008, pp. 687-690.

[46] T. Yuge and S. Sasaki, "Train Radio System using Leaky Coaxial Cable," in 34th IEEE Vehicular Technology Conference, vol. 34, May 1984, pp. $43-48$.

[47] K. Ishizu et al., "Bullet-train Network Architecture for Broadband and Real-time Access," in 12th IEEE Symposium on Computers and Communications, (ISCC 2007), Aveiro, Portugal, July 2007, pp. 241248.

[48] G. Bianchi et al., "Internet Access on Fast Trains: 802.11-based onboard wireless distribution network alternatives," in 12th IST Mobile \& Wireless Communications Summit, Aveiro, Portugal, June 2003, pp. $15-18$.

[49] ACCORDE. (2008) ACORDE - Broadband Railway Internet Access on High Speed Trains Via Satellite Links. Press release. Accorde. Santander, Spain. [Online]. Available: http://www.railway-technology. com/contractors/signal/acorde/

[50] J. Thornton, "Tracking Multi-Beam Lens Antenna-the Gain of a Dish in Half the Height," Presented at the IET Seminar on Broadband on Trains, London, UK, Apr 2009.

[51] M. Aguado et al., "WiMax on Rails," Vehicular Technology Magazine, IEEE, vol. 3, no. 3, pp. 47-56, Sept. 2008.

[52] K. R. Kumar et al., "SWiFT: A Novel Architecture for Seamless Wireless Internet for Fast Trains," in IEEE Vehicular Technology Conference, (VTC Spring 2008), Singapore, May 2008, pp. 3011-3015.

[53] Draft Standard for Local and Metropolitan Area Networks: Media Independent Handover Services, Draft Standard, IEEE Working document 802.21/D005.00, Apr 2007.

[54] G. P. White and Y. V. Zakharov, "Data Communications to Trains From High-Altitude Platforms," Vehicular Technology, IEEE Transactions on, vol. 56, no. 4, pp. 2253-2266, July 2007.

[55] N. Lomas. (2008, March 26) High speed TGV trains get online. News story. [Online]. Available: http://networks.silicon.com/mobile/0, 39024665,39170481,00.htm

[56] D. Sivchenko et al., "Internet Traffic Performance in High Speed Trains," in HET-NETs '04: Second Int'l Working Conf.: Performance Modelling and Evaluation of Heterogeneous Networks, Ilkley, UK, July 2004, pp. $26-31$.

[57] I. Gaspard and G. Zimmermann, "Investigations for Broadband Internet within High-speed Trains," Advances in Radio Science, vol. 3, no. 13, pp. 247-252, May 2005.

[58] F. Ceprani and V. Schena, "FIFTH Project Solutions Demonstrating New Satellite Broadband Communication System for High Speed Train," in VTC 2004: Proceedings of the 59th IEEE Vehicular Technology Conference, Spring, vol. 5, Milan, Italy, May 2004, pp. 2831-2835.

[59] SNCF. (2007) TGV Launches its new Services and Internet Access Portal. Press release. SNCF. [Online]. Available: http: //www.appearnetworks.com/UserFiles/File/SNCF_press_kit_english.pdf

[60] J.-P. Rodrigue et al., The Geography of Transport Systems. New York, NY USA: Routledge, 2006, ch. 3.Transportation Modes, p. 284.

[61] E. M. M. zu Hörste, "Use of Broadband Communication for Information and Control Purposes in Railways," Presented at ITST '07: 7th Int'l Conf. ITS Telecommunications, Sophia Antipolis, France, June 2007, pp. 1-3.

[62] A. Fabri et al., "Use of the Internet for Remote Train Monitoring and Control: the ROSIN Project," Presented at the Rail Technology Conference, London, United Kingdom, Sep 1999.

[63] H. Kirrmann and P. Zuber, "The IEC/IEEE Train Communication Network," Micro, IEEE, vol. 21, no. 2, pp. 81-92, Mar/Apr 2001.
[64] "EDGE: Introduction of high-speed data in GSM/GPRS networks," Technical paper, 2005. [Online]. Available: http://www.ericsson.com/ solutions/tems/library/tech_papers/tech_related/edge_wp_technical.pdf

[65] J. Saw, "A Mobile Operator's Experience on Delivering Broadband Connectivity on Trains," Presented at the Wireless Broadband Conference. London, United Kingdom: The Institution of Engineering and Technology, Apr 2006, pp. 17-27.

[66] B. Lannoo et al., "Business Model for Broadband Internet on the Train," in Proc. 46th Federation of Telecommunications Engineers of the European Community Congress (FITCE 2007), Warsaw, Poland, Aug 2007, pp. 60-66.

[67] D. Lundberg and P. Gunningberg, "Feasibility Study of WLAN Technology for the Uppsala - Stockholm Commuter Train,” Department of Information Technology, Uppsala University, Tech. Rep., June 2004.

Daniel T. Fokum [S'07] (fokumdt@ittc.ku.edu) is a $\mathrm{PhD}$ candidate in Computer Science in the Department of Electrical Engineering and Computer Science at the University of Kansas. Prior to joining the University of Kansas in 2006, he worked in industry for six years. He received his M.S. degree from the University of Missouri-Kansas City in 2005, and his B.A. degree from Park University in 2000, both in Computer Science. He is a member of the IEEE Computer Society, IEEE Communication Society, and the ACM. His research interests include sensor network design, provision of quality of service in wireless networks, and concurrency control in databases.

Victor S. Frost [S'75-M'82-SM'90-F'98] received the B.S., M.S., and Ph.D. degrees from the University of Kansas, Lawrence, in 1977, 1978, and 1982, respectively. In 1982, he joined the faculty of the University of Kansas and is the Dan F. Servey Distinguished Professor of Electrical Engineering and Computer Science. Currently, he is serving as a program director in the Computer and Network Systems (CNS) division of the Computer and Information Science and Engineering (CISE) Directorate at the National Science Foundation. He is a Fellow of the IEEE and received a Presidential Young Investigator Award from the National Science Foundation in 1984. He was the Director of the KU Telecommunications and Information Technology Center (ITTC) for over ten years. From 1987 to 1996 Dr. Frost was the Director of the KU Telecommunications and Information Sciences Laboratory. His current research interests include communications systems and networks, networking testbeds, internet quality of service, traffic management, and integrated broadband communication networks. He has been involved in research on several national scale high speed wide area testbeds; he was an investigator on a gigabit testbed (MAGIC) research effort and ACTS ATM Internetwork (AAI). Government agencies, including, NSF, DARPA, Rome Labs, and NASA have sponsored his research. Dr. Frost has been involved in research for numerous corporations, including Sprint, NCR, Nortel, Telesat Canada, AT\&T, McDonnell Douglas, DEC, and COMDISCO Systems. He has been principal investigator on over thirty five research efforts and involved as co-investigator on over forty projects. As a result of those efforts he has published over 100 journal articles and conference papers. Dr. Frost was listed Kansas City Star "Tech 50" in 2000 and 2002. He was elected to the IEEE Communications Society Board of Governors as a Member at Large for the 2008-2011 term. He is currently the Area Editor for Communications Simulation for ACM Transactions on Simulation and Modeling of Computer Systems. 